\title{
Youth Athletes' Moral Decision Making Levels and Sportspersonship Behavior Levels of Coaches
}

\author{
Ömür F. Karakullukçu ${ }^{1}$ \\ ${ }^{1}$ Ankara Hacı Bayram Veli University, Department for Administrative and Financial Affairs, Ankara, Turkey \\ Correspondence: Ömür F. Karakullukçu, Ankara Hacı Bayram Veli University, Department for Administrative and \\ Financial Affairs, Ankara, Turkey. E-mail: karakullukcu@hbv.edu.tr
}

Received: October 15, 2019

Accepted: December 3, 2019

Online Published: February 27, 2020

doi:10.5539/ies.v13n4p8

URL: https://doi.org/10.5539/ies.v13n4p8

\begin{abstract}
The aim of this study is to determine moral decision making attitudes of youth athletes and sportspersonship behavior levels of their coaches; and to test them in terms of certain variables. The study is in a descriptive research model; the sample group consists of 294 certified athletes playing in youth sports teams; the ages range between 11 and 17. As measurement, "Attitudes to Moral Decision-Making in Youth Sport Questionnaire-2 (AMDYSQ-2)" and "Sportspersonship Coaching Behaviors Scale (SCBS)" were used.

In order to test whether the data meet the prerequisite for multivariable tests, Skewness and Kurtosis values and Levene and Box $\mathrm{M}$ values were investigated. In the analysis of data, descriptive statistics methods, MANOVA, ANOVA and Pearson Correlation analysis were used. In order to determine the reliability of scales, their Cronbach Alpha internal consistency coefficients were calculated.

MANOVA results show that AMDYSQ-2 has a significant impact on all independent variables whereas SCBS has a significant impact on "gender" and "branch involvement duration" variables. According to the correlation results, there is a positive and low-level significant correlation between "acceptance of cheating" and "keep winning in proportion" factors of SCBS and "setting expectations for good sportspersonship", "teaching good sportspersonship", "reinforcing sportspersonship", "prioritizing winning over good sportspersonship" and "modeling good sportspersonship" factors of AMDYSQ-2.

As a result, it is concluded that for the athletes, "acceptance of cheating" factor of AMDYSQ-2 and "setting expectations for good sportspersonship" factor of SCBS are the most important factors.
\end{abstract}

Keywords: moral decision making, amateur, team sports, youth sports athlete

\section{Introduction}

When the literature related to recreation is investigated, it is seen that today leisure opportunities of individuals has been increasing (Güngörmüss, 2007) and it is a fact that this increase required leisure activity tendencies (Güngörmüş et al., 2006). How individuals make use of this period of time both for themselves and for their families has become a research subject for the last 20 years (Çimen \& Sarol, 2017; Güngörmüş et al., 2014; Ayyıldı-Durhan, 2019; Gürbüz \& Henderson, 2013; Gümüş et al., 2018; Güler \& Turkmen, 2018; Gürbüz \& Henderson, 2014). It is obvious that the intensity of the researches related to physical activity and sports events are supported in order to increase in quantitative and qualitative terms (Güngörmüş et al., 2019; Morton et al., 2016). In addition, lack of physical activity, which has become one of the greatest problems of our era, and inactivity, which has gradually become a life-style, lead to the increase in illnesses such as gaining excessive weight, cardiovascular illnesses, diabetes (Orhan, 2019). In order to be safe from stress and lack of physical activity and illnesses related to those, sports culture, national-level strategies and community programs must be formed, as suggested by Gordon-Larsen et al. (2000).

Previous research reveals that regular physical exercise ascertains affective and behavioral differences in leisure attitude (Kara et al., 2019) and physical exercise and sports have valuable contributions to gaining self-confidence, learning about body, socializing, discovering the world, growing up and improving healthily for the children (Soulliard et al., 2019). In this frame, that our children take the aforementioned education fundamentally in their families, immediate environment, educational institutions, and sports schools/sports clubs forms the base of sports culture. Güven and Öncü (2006) emphasized that the involvement of the children in physical education and sports 
activities is majorly related to the perspective of parents about the subject; and that the approaches of the families are the most determinative element in point whether the children participate in the activities or not.

Another important aspect to consider is moral development. Moral development is to obtain morality and moral behavior by social learning, imitation of others and modeling after others (Bandura, 1986, 1991, 2001). On the other, according to Kohlberg (1977), moral judgment has three stages as follows: pre-conventional reasoning, conventional reasoning, and post-conventional reasoning. In the pre-conventional reasoning stage, an individual does not develop an internalized moral judgment and is fueled by rewards and punishments in terms of moral development. In the conventional reasoning stage, the individual is mainly affected by parents and social environment and its laws. In the post-conventional reasoning stage, the individual internalizes moral reasoning without any control over his/her behavior from outside. When all these are considered, it can be said that coaches and parents can affect the moral decision-making process of young individuals in various ways.

Physical education should be instructed with a coach/trainer in order to reveal the acquisitions of sports. However, phenomena inside the sports such as competition and ambition towards winning affect moral decision making and sportspersonship behaviors positively/negatively (Alemdağ, 2019; Mallia et al., 2019). It is an undeniable fact that the moral attitude and behaviors of especially youth-sports athletes are affected by technical and tactical skills and training capacity of coaches along with their strong behaviors that can bring victory to their athletes/teams; in addition their contribution to the result of the competitions (Spruit et al., 2019).

When the competition is evaluated in this scope, coaches form positive or negative models in terms of leading athletes to right and wrong behavior, and they support sportspersonship behavior in athletes with their feedbacks, they teach what the right behaviors should be when athletes come across with moral dilemmas, and lastly, coaches can create a motivational climate in order to present sportsperson-like behaviors (Bolter \& Weiss, 2013). Besides, coaches that become role models for athletes have a significant effect on the moral dimensions of the athletes (Trevino, Hartman, \& Brown, 2000) in addition to becoming the closest role models affecting athletes (Sezen-Balçıkanlı, Aktaş, \& Sezen, 2018). This significant correlation between coach behavior and moral decision-making levels of athletes has led the researchers to investigate the subject deeply. When the studies in other countries are evaluated, it is seen that the number of studies on this matter has increased (Delrue et al., 2017; Johnson et al., 2018); however, it is also seen that the studies carried out in Turkish culture are still in a limited level (Gürpınar, 2014; Gençer et al., 2019; Gümüş, 2019; Y. Yıldız, K. Yıldız, \& Tutucu, 2019). In the light of the information, the aim of the current study is to investigate the moral decision making attitudes of youth-sports athletes and the behaviors of the sportspersonship of their coaches.

\section{Method}

\subsection{Participants}

The sample group of the study in a descriptive research model consists of 294 certified athletes $\left(\right.$ Mean $\left._{\text {age }}=13.69 \pm 1.93\right) 157$ female $\left(\right.$ Mean $\left._{\text {age }}=13.44 \pm 1.93\right)$ and 137 male $\left(\right.$ Mean $\left._{\text {age }}=13.97 \pm 1.90\right)$ playing in youth sports teams in Manisa (football, volleyball, handball, and basketball). Their ages range from 11 to 17.

\subsection{Materials}

As measurement, "Attitudes to Moral Decision-Making in Youth Sport Questionnaire-2" (AMDYSQ-2) developed by Lee, Whitehead, and Ntoumanis (2013) adapted into Turkish society by Gürpınar (2014) and "Sportspersonship Coaching Behaviors Scale" (SCBS) developed by Bolter and Weiss (2013) and adapted into Turkish by Sezen-Balçıkanlı (2018) were used.

Demographic Information Form: "Demographic Information Form" developed by the researcher consists of questions related to independent variables such as "gender, branch, branch involvement duration and working with the coach duration" which are the study subject of the research in order to collect information about the youth sports athletes.

Attitudes to Moral Decision-Making in Youth Sport Questionnaire-2: Attitudes to Moral Decision-Making in Youth Sport Questionnaire (AMDYSQ) was first developed by Lee et al. (2007). The Turkish adaptation of the scale was carried out by Gürpınar (2014). However, the second version of the scale, Attitudes to Moral Decision-Making in Youth Sport Questionnaire-2 (AMDYSQ-2), developed by Lee, Whitehead, and Ntoumanis (2013) and adapted into Turkish culture with reliability and validity studies by Gürpınar (2014), has 3 factors, 15 items, in the form of 5 Likert type questionnaire. Items are scored between (1) Strongly Disagree and (5) Strongly Agree. The subscales consist of "Acceptance of Gamesmanship (AG)", Acceptance of Cheating (AC)" and "Keep Winning in Proportion (KWIP)".

Sportspersonship Coaching Behaviors Scale: "Sportspersonship Coaching Behaviors Scale" (SCBS) developed by 
Bolter and Weiss (2013) and adapted into Turkish by Sezen-Balçıkanlı (2018) is a 24-item and 6-factor scale. Items are scored between (1) never and (5) quite often in the form of 5 Likert type questionnaire. Negative expressions in the scale are scored reversely.

\subsection{Data Analysis}

In order to apply the data collection tools to youth-sports athletes, company executives of the sports clubs were primarily informed about the aim of the current study and necessary permissions were taken. Next, the data collection tools were handed before their training or after their training in order not to make the athletes feel uncomfortable and to make them answer the questions sincerely. In the process of application and collection of the questionnaires, the researcher paid great attention to privacy and voluntary participation in this study. The forms that are incomplete or filled in a wrong way were checked and excluded from the study. The valid and acceptable questionnaires (294 data) were transferred to the electronic environment in order to be evaluated.

The statistical analyses done in the current study were carried out with SPSS 21 statistics package program. In the evaluation of the data, frequency, arithmetic mean, standard deviation were used; on the other hand, single-factor MANOVA, ANOVA and Pearson Correlation tests were used for the independent samples. In order to test whether the data meet the prerequisite for multivariable tests, the Skewness and Kurtosis values (Büyüköztürk, 2012; Kline, 2011) and Levene and Box M values were investigated. In the analysis of obtained data descriptive statistics methods, MANOVA, ANOVA and Pearson Correlation analyses were used. In order to determine the reliability of scales, their Cronbach Alpha internal consistency coefficients were calculated.

\section{Results}

Table 1. Distribution of scale scores

\begin{tabular}{cccccccccc}
\hline Sub-scales & Item No & $\mathrm{N}$ & Min & Max & Mean & SD & Skewness & Kurtosis & C. Alpha \\
\hline AMDYSQ-2 & 15 & & & & & & & & 0.83 \\
AC & 6 & & 2.00 & 5.00 & 4.26 & 0.79 & -1.00 & 0.14 & 0.83 \\
AG & 6 & & 1.00 & 5.00 & 3.20 & 0.93 & -0.09 & -0.76 & 0.78 \\
KWIP & 3 & & 1.00 & 5.00 & 4.06 & 0.82 & -0.76 & 0.20 & 0.75 \\
SCBS & 24 & & & & & & & & 0.91 \\
Expectation & 4 & 294 & 1.25 & 5.00 & 4.40 & 0.71 & -1.39 & 1.41 & 0.77 \\
Punishing & 4 & & 1.25 & 5.00 & 3.68 & 0.94 & -0.36 & -0.64 & 0.77 \\
Teaching & 4 & & 1.50 & 5.00 & 4.36 & 0.70 & -1.33 & 1.44 & 0.76 \\
Reinforcing & 4 & & 1.00 & 5.00 & 3.85 & 0.88 & -0.73 & 0.34 & 0.78 \\
Winning & 4 & & 1.00 & 5.00 & 3.70 & 0.93 & 0.48 & -0.85 & 0.84 \\
Model & 4 & & 1.50 & 5.00 & 4.25 & 0.88 & -1.35 & 1.15 & 0.83 \\
\hline
\end{tabular}

When the scores obtained by the participants for three factors of AMDYSQ-2 are evaluated, the first factor is "acceptance of cheating" (Mean=4.26) followed subsequently by "acceptance of gamesmanship" (Mean=4.06) and "keep winning in proportion" (Mean=3.68). It is seen that the Cronbach Alpha internal consistency coefficient which is calculated to test the reliability of the scale ranges from 0.75 to 0.83 . The total Cronbach Alpha internal consistency coefficient calculated for the scale total is 0.83 . Also when the scores obtained by the participants for six factors of SCBS are evaluated, the first factor is "setting expectations for good sportsmanship" (Mean=4.40) and the last factor is "prioritizing winning over good sportsmanship" (Mean=2.30). ). It is seen that the Cronbach Alpha internal consistency coefficient which is calculated to test the reliability of the scale ranges from 0.76 to 0.84 and the total Cronbach Alpha internal consistency coefficient calculated for the scale total is 0.77 . 
Table 2. Analysis results of the participants for gender variable

\begin{tabular}{|c|c|c|c|c|c|c|c|}
\hline & & \multicolumn{2}{|c|}{ Female $(N=157)$} & \multicolumn{2}{|c|}{ Male $(N=137)$} & \multirow{2}{*}{ F } & \multirow{2}{*}{$\mathrm{p}$} \\
\hline & & Mean. & $\mathrm{Sd}$ & Mean. & $\mathrm{Sd}$ & & \\
\hline \multirow{3}{*}{ AMDYSQ-2 } & $\mathrm{AC}$ & 4.37 & 0.71 & 4.14 & 0.85 & 6.332 & $0.012 *$ \\
\hline & AG & 3.37 & 0.93 & 3.02 & 0.91 & 10.646 & $0.001 *$ \\
\hline & KWIP & 4.12 & 0.76 & 3.98 & 0.89 & 2.137 & 0.145 \\
\hline \multirow{6}{*}{ SCBS } & Expectation & 4.46 & 0.71 & 4.33 & 0.71 & 2.165 & 0.142 \\
\hline & Punishing & 3.57 & 0.99 & 3.79 & 0.87 & 3.969 & $0.047 *$ \\
\hline & Teaching & 4.43 & 0.67 & 4.28 & 0.73 & 3.487 & 0.063 \\
\hline & Reinforcing & 3.80 & 0.90 & 3.91 & 0.86 & 1.018 & 0.314 \\
\hline & Winning & 3.88 & 1.14 & 3.30 & 1.08 & 8.065 & $0.005^{*}$ \\
\hline & Model & 4.43 & 0.74 & 4.05 & 0.98 & 13.608 & $0.000^{*}$ \\
\hline
\end{tabular}

According to MANOVA results in Table 2, it is seen that "gender" variable has a significant main impact on the factors of AMDYSQ-2 $\left[\lambda=0.958, \mathrm{~F}_{(3,290)}=4.229 ; \mathrm{p}<0.05\right]$. It is concluded that "acceptance of cheating" and "acceptance of gamesmanship" mean scores differ significantly in terms of "gender" variable main impact in mean scores of the participants' factor level. In the factors where significant difference was found, female participants obtained higher scores than male participants.

Also when the results are evaluated, it is seen that "gender" variable has a significant main impact on the factors of SCBS $\left[\lambda=0.890, \mathrm{~F}_{(6,287)}=5.921 ; \mathrm{p}<0.05\right]$. When the results are evaluated in order to understand which dependent variable contributed to multivariate significance, it is concluded that "punishing poor sportspersonship", "prioritizing winning over good sportspersonship" and "modeling good sportspersonship" mean scores differ significantly in terms of "gender" variable main impact. In the factors where significant difference was found, male participants obtained higher scores than female participants in "punishing poor sportspersonship" and "prioritizing winning over good sportspersonship" whereas female participants obtained higher scores than male participants "modeling good sportspersonship".

Table 3. Analysis results of the participants for branch variable

\begin{tabular}{|c|c|c|c|c|c|c|c|c|c|c|c|}
\hline & & \multicolumn{2}{|c|}{$\begin{array}{c}\text { Basketball } \\
\quad(\mathrm{N}=83)\end{array}$} & \multicolumn{2}{|c|}{$\begin{array}{l}\text { Football } \\
(\mathrm{N}=79)\end{array}$} & \multicolumn{2}{|c|}{$\begin{array}{l}\text { Handball } \\
(N=35)\end{array}$} & \multicolumn{2}{|c|}{$\begin{array}{l}\text { Volleyball } \\
\qquad(N=97)\end{array}$} & \multirow[t]{2}{*}{$\mathrm{F}$} & \multirow[t]{2}{*}{$\mathrm{p}$} \\
\hline & & Mean & $\mathrm{Sd}$ & Mean & $\mathrm{Sd}$ & Mean & $\mathrm{Sd}$ & Mean & $\mathrm{Sd}$ & & \\
\hline \multirow{3}{*}{ AMDYSQ-2 } & $\mathrm{AC}$ & 4.16 & 0.77 & 4.20 & 0.84 & 4.20 & 0.85 & 4.40 & 0.73 & 1.709 & 0.165 \\
\hline & AG & 3.00 & 1.01 & 3.22 & 0.91 & 3.28 & 0.88 & 3.33 & 0.88 & 1.958 & 0.120 \\
\hline & KWIP & 4.10 & 0.80 & 4.04 & 0.87 & 4.19 & 0.82 & 3.98 & 0.82 & 0.697 & 0.555 \\
\hline \multirow{6}{*}{ SCBS } & Expectation & 4.20 & 0.77 & 4.44 & 0.63 & 4.46 & 0.67 & 4.51 & 0.70 & 3.225 & $0.023^{*}$ \\
\hline & Punishing & 3.86 & 0.85 & 3.80 & 0.86 & 3.93 & 0.82 & 3.33 & 1.03 & 7.141 & $0.000 *$ \\
\hline & Teaching & 4.28 & 0.75 & 4.40 & 0.63 & 4.41 & 0.73 & 4.39 & 0.70 & 0.579 & 0.629 \\
\hline & Reinforcing & 3.95 & 0.87 & 3.93 & 0.78 & 4.14 & 0.75 & 3.60 & 0.97 & 4.610 & $0.004^{*}$ \\
\hline & Winning & 3.53 & 1.26 & 3.35 & 1.13 & 4.02 & 1.10 & 4.02 & 0.90 & 7.088 & $0.000 *$ \\
\hline & Model & 4.07 & 1.01 & 4.24 & 0.73 & 4.30 & 1.08 & 4.40 & 0.76 & 2.253 & 0.082 \\
\hline
\end{tabular}

According to analysis results, "branch" variable does not have a significant main impact on the factors of AMDYSQ-2 $\left[\lambda=0.951, \mathrm{~F}_{(3,290)}=1.640 ; \mathrm{p}>0.05\right]$. Also the mean scores of the participants in factor level do not have a statistically significant difference.

According to MANOVA results, "branch" variable has a significant main impact on the factors of SCBS $[\lambda=0.753$, $\left.\mathrm{F}_{(6,287)}=4.729 ; \mathrm{p}<0.05\right]$. When the results are evaluated in order to understand which dependent variable contributed to multivariate significance, it is found that the mean scores of "setting expectations for good sportpersonship", "punishing poor sportspersonship", "reinforcing good sportspersonship" and "prioritizing winning over good sportspersonship" differ significantly in terms of "branch" variable main impact. In the factor of "setting expectations for goodsportspersonship" where significant difference was found, volleyball players scored higher than basketball players. In the factor of "punishing poor sportspersonship", the mean scores of volleyball players are lower than the other three groups. In the factor of "reinforcing good sportspersonship", volleyball players scored higher than basketball and handball players and in "prioritizing winning over good 
sportspersonship", the mean scores of volleyball and handball players are statistically higher than the other two groups.

Table 4. Analysis results of the participants for branch involvement duration variable

\begin{tabular}{|c|c|c|c|c|c|c|c|}
\hline & & \multicolumn{2}{|c|}{$1-2$ years $(N=114)$} & \multicolumn{2}{|c|}{3 years and over $(N=180)$} & \multirow{2}{*}{$\mathrm{F}$} & \multirow{2}{*}{$\mathrm{p}$} \\
\hline & & Mean & $\mathrm{Sd}$ & Mean & $\mathrm{Sd}$ & & \\
\hline \multirow{3}{*}{ AMDYSQ-2 } & $\mathrm{AC}$ & 4.32 & 0.66 & 4.22 & 0.86 & 1.104 & 0.294 \\
\hline & $\mathrm{AG}$ & 3.36 & 0.91 & 3.10 & 0.94 & 5.425 & $0.021 *$ \\
\hline & KWIP & 4.19 & 0.79 & 3.97 & 0.83 & 5.034 & $0.026^{*}$ \\
\hline \multirow{6}{*}{ SCBS } & Expectation & 4.17 & 0.81 & 4.54 & 0.59 & 20.162 & $0.000^{*}$ \\
\hline & Punishing & 3.55 & 0.96 & 3.76 & 0.92 & 3.395 & 0.066 \\
\hline & Teaching & 4.26 & 0.72 & 4.43 & 0.68 & 3.770 & 0.053 \\
\hline & Reinforcing & 3.80 & 0.86 & 3.88 & 0.90 & 0.681 & 0.410 \\
\hline & Winning & 3.59 & 1.14 & 3.77 & 1.12 & 1.739 & 0.188 \\
\hline & Model & 4.10 & 0.92 & 4.35 & 0.84 & 5.824 & $0.016^{*}$ \\
\hline
\end{tabular}

When Table 4 is evaluated, it is seen that "branch involvement duration" variable has a significant impact on AMDYSQ-2 factors $\left[\lambda=0.970, \mathrm{~F}_{(3,290)}=2.969 ; \mathrm{p}<0.05\right]$. On the other hand, it is concluded that "acceptance of gamesmanship" and "keep winning in proportion" mean scores differ significantly in terms of "branch involvement duration" main impact in the mean scores of the participants' factor level. In the factors where significant difference occurs, the participants who are involved in the branch for " $1-2$ years" have higher scores that the participants involved in the branch for 3 years or more.

When the results are considered, it is found that "branch involvement duration" has a significant impact on SCBS factors $\left[\lambda=0.922, \mathrm{~F}_{(6,287)}=4.048 ; \mathrm{p}<0.05\right]$. When the data are evaluated in terms of which dependent variable creates the multivariate significance, the mean scores of "setting expectations for good sportspersonship" and "modeling for good sportspersonship" has a statistically significant difference in terms of "branch" variable; and it is found that the participants involved in the branch for 3 years or more scored higher.

Table 5. Correlation between AMDYSQ-2 and SCBS

\begin{tabular}{cccc}
\hline & $\mathrm{AC}$ & $\mathrm{AG}$ & $\mathrm{KWIP}$ \\
\hline Expectation & $0.293^{* *}$ & 0.059 & $0.200^{* *}$ \\
Punishing & -0.005 & -0.030 & 0.062 \\
Teaching & $0.250^{* *}$ & 0.013 & $0.242^{* *}$ \\
Reinforcing & $0.120^{*}$ & -0.028 & $0.128^{*}$ \\
Winning & $0.222^{* *}$ & -0.075 & $0.193^{* *}$ \\
Model & $0.224^{* *}$ & 0.88 & $0.215^{* *}$ \\
\hline
\end{tabular}

Correlation analysis results show that there is a positive and low level significant correlation between "acceptance of cheating" and "keeping winning in proportion" factors of SCBS and "setting expectation for good sportspersonship", "teaching good sportspersonship", "reinforcing good sportspersonship", "prioritizing winning over good sportspersonship" and "modeling good sportspersonship" factors of AMDYSQ-2.

\section{Discussion and Conclusion}

When the results are considered, "acceptance of cheating" and "acceptance of gamesmanship" mean scores differ significantly in terms of AMDYSQ-2 for "gender" variable main impact; and female participants have higher scores than male participants in both factors. When the literature is evaluated, Atalay (2016) found that there is a statistically significant difference in "acceptance of cheating" and "acceptance of gamesmanship" in terms of gender variable. It was found that male athletes have higher scores in "acceptance of cheating" and "acceptance of gamesmanship" whereas no significant difference was found in "keep winning in proportion". Also, Gürpınar (2014) determined that scores that athletes obtained from "acceptance of cheating", "acceptance of gamesmanship" and "keep winning in proportion" subscales differ significantly in favor of females in the study on moral decision making attitudes of secondary and high school students. It was also found in the study that female students accept "cheating and gamesmanship" less than males; however, they keep winning in proportion more. 
Besides, Lee et al. (2007) determined that women score higher in "keep winning in proportion" subscales when compared to men; and men scored higher in "acceptance of cheating" and "acceptance of gamesmanship. Çağlayan et al. (2017) similarly found that women studying at sports sciences field have higher moral attitudes when compared to men. As a result of the study carried out by Y. Y1ldız, K. Yıldız, and Tutucu (2019), it is stated that female athletes have higher moral decision making level than male athletes. The results in the literature show parallelism with the result of our study. When considered in the light of this, moral decision making attitudes are in favor of women in terms of gender variable.

Also when the results are evaluated, "punishing poor sportspersonship", "prioritizing winning over good sportspersonship" and "modeling for good sportspersonship" mean scores differ significantly in terms of SCBS for "gender" variable main impact. In the factors where significant difference was determined, male participants have higher scores in "punishing poor sportspersonship" and "prioritizing winning over good sportspersonship" whereas female participants scored higher in "modeling for good sportspersonship". Bolter (2010) determined that female athletes scored higher in subscales of "setting expectations for good sportspersonship", "modeling for good sportspersonship" and "teaching good sportspersonship"; however, male athletes scored higher in "punishing poor sportspersonship" and prioritizing winning over good sportspersonship". The results show similarities with the current study. In contrast to our study, Miller et al. (2004) found no significant difference between boys and girls in their study.

According to analysis results, it is seen that "branch" variable does not have a statistically significant difference in the mean scores of participants in AMDYSQ-2 factor level. When the literature is evaluated, Atalay (2016) found that "acceptance of cheating" and "acceptance of gamesmanship" scores of futsal players are high and the reason of which is that the tension of competition reaches its peak point with the rushing competition period. In "keep winning in proportion" subscale, volleyball players obtained high scores. Özsarı and Altın (2017) found that "acceptance of gamesmanship" is higher in wresters than in participants involved in athletics. However, no significant difference was found in "acceptance of cheating" and "keep winning in proportion". Thus in the light of literature review, it can be said that each sports branch has its own features and these characteristics cause changes in the result of each sport branch. Şirin et al. (2017) couldn't determine a significant difference in "acceptance of cheating" in their study on different martial arts athletes whereas the athletes involved in karate have higher scores in "acceptance of gamesmanship" and "keep winning in proportion" than the ones involved in wrestling, taekwondo, boxing, judo and kickboxing. Gürpınar (2014) found that footballers have lower scores in moral decision making attitudes than the other branches; and volleyball players have the highest scores. Besides, the scores of the athletes involved in branches requiring no body-contact differ significantly in terms of all factors when compared to the scores of the athletes involved in branches requiring physical contact. Similarly, Yildiz (2016) investigated the moral disengagement levels of sports fans and revealed that the moral disengagement levels of sports fans increases as their ages decrease. According to Gürpınar (2014), the athletes doing sports requiring no physical contact accept cheating and gamesmanship less by keep winning in proportion. Mouratidou et al. (2007) found that the moral improvement scores of the athletes in no/low of level of physical contact are higher. The idiosyncrasy and competitive level of a sports branch is utmost determiner of the occurrence of moral attitude and behavior (Cited by Atalay, 2016).

According to MANOVA results, "setting expectations for good sportspersonship", "punishing poor sportspersonship", "prioritizing winning over good sportspersonship" and "reinforcing for good sportspersonship" mean scores differ significantly in terms of SCBS for "branch" variable main impact. In "setting expectations for good sportspersonship" factor, volleyball players have higher mean scores than basketball players. In "punishing poor sportspersonship" factor, volleyball players scored lower than the other three groups. In "reinforcing good sportspersonship" factor, the mean scores of volleyball players are higher than basketball and handball players; and in "prioritizing winning over sportspersonship" factor, the mean scores of volleyball and handball players are statistically higher than the other two groups. Although there are limited studies on SCBS, there are studies on the behaviors of coaches and their effects on athletes. In the study of Aleksić-Veljković et al. (2016), it is stated that the behavior styles of individual and team sports coaches and their interactions with the athletes can differ. Also it is concluded that while coach-athlete relationship can be more independent in individual sports, the coach-athlete relationship in team sports can be more formal, hierarchical and flexible. Besides, it is determined that when the coaches show positive emotions and behaviors, it makes the athletes believe in themselves more, and it creates positive impacts for future opportunities. According to results, "acceptance of gamesmanship" and "keep winning in proportion" factors' mean scores differ significantly in terms of AMDYSQ-2 for "branch involvement duration" variable main impact. The mean scores of the athletes involved in the branch for "1-2 years" are higher than the athletes involved in the branch for " 3 years or more". Alemdağ (2019) found that "sports year" variable cause a 
significant difference in moral decision making attitudes of young athletes and that an increase in "sports year" causes an increase in "acceptance of cheating" and "keep winning in proportion" sub-scales. However, it creates a decrease in "acceptance of gamesmanship" subscale.

As a result, although moral decision making attitude subscale mean scores of youth-sports athletes, the male athletes playing football or basketball have lower scores in "prioritizing winning over good sportspersonship" than others. These mean scores become gradually higher when the athletes become adults and the negative sides of today's decision making behaviors become apparent. Consequently, the study suggest that regular trainings should be given by schools and ministries through sports clubs both in these branches and age groups and in other branches and ages.

\section{References}

Aleksić-Veljković, A., Dimić, I., Mujanović, R., \& Živčić-Marković, K. (2016). College athletes’ perceptions of coaching behaviours: Differences between individual and team sports. Baltic journal of sport \& health sciences, 101(2), 61-65. https://doi.org/10.33607/bjshs.v2i101.57

Alemdag, S. (2019). Investigation of prosocial and antisocial behaviors of young athletes in terms of moral decision making attitudes. Pedagogics, psychology, Medical-Biological Problems of Physical Training and Sports, 23(3), 112-117. https://doi.org/10.15561/18189172.2019.0301

Atalay, A. (2016). Moral decision making attitudes of the student athletes studying at universities in Turkey. The Journal of Academic Social Science, 31(4), 53-66. https://doi.org/10.16992/ASOS.1331

Ayyıldı-Durhan, T. (2019). A Study on the Effect of Personal Values on Leisure Motivation. International Journal of Recreation and Sports Science, 3(1), 25-38. Retrieved from https://dergipark.org.tr/en/pub/ijrss/issue/46673/455766

Bandura, A. (1986). Social Foundations of Thought and Action: A Social Cognitive Theory. Englewood Cliffs, NJ, Prentice-Hall.

Bandura, A. (1991). Social cognitive theory of moral thought and action. In W. M. Kurtines, \& J. L. Gewirtz (Eds.), Handbook of moral behavior and development: Theory, research and applications. Hillsdale, NJ: Erlbaum.

Bandura, A. (2001). Social cognitive theory: An agentic perspective. Annu Rev. Psychol., 52, 1-26. https://doi.org/10.1146/annurev.psych.52.1.1

Bolter, N. D. (2010). Coaching for character: Mechanisms of influence on adolescent athletes' sportsmanship (Unpublished doctoral dissertation). Retrieved from https://conservancy.umn.edu/bitstream/handle/11299/ 95905/Bolter_umn_0130E_11394.pdf?sequence=1\&isAllowed=y

Bolter, N. D., \& Weiss, M. R. (2013). Coaching behaviors and adolescent athletes' sportspersonship outcomes: Further validation of the sportspersonship coaching behaviors scale (SCBS). Sport, Exercise, and Performance Psychology, 2, 32-47. https://doi.org/10.1037/a0029802

Büyüköztürk, Ș. (2012). Sosyal Bilimler için veri analizi el kitabı. Ankara: Pegem Akademi.

Çağlayan, A., Özbar, N., Türkmen, N., \& Öntürk, Y. (2017). An analysis on moral decision-making attitudes of the faculty of sports sciences and school of physical education and sports undergraduates. International Journal of Psychiatry and Psychological Researches, 10, 20-42.

Delrue, J., Vansteenkiste, M., Mouratidis, A., Gevaert, K., Broek, G. V., \& Haerens, L. (2017). A game-to-game investigation of the relation between need-supportive and need-thwarting coaching and moral behavior in soccer. Psychology of Sport and Exercise, 31, 1-10. https://doi.org/10.1016/j.psychsport.2017.03.010

Gencer, Y., Eroğlu, O., \& Yıldırım, Y. (2019). Investigation of Sportsmanship Behaviors of Athletes Participating in Intercollegiate Basketball Competitions. International Journal of Recreation and Sports Science, 3(1), 39-45. Retrieved from https://dergipark.org.tr/en/pub/ijrss/issue/46673/477097

Gordon-Larsen, P., McMurray, R. G., \& Popkin, B. M. (2000). Determinants of adolescent physical activity and inactivity patterns. Pediatrics, 105(6), e83-e83. https://doi.org/10.1542/peds.105.6.e83

Güler, H., \& Türkmen, M. (2018). Investigation of the effects of leisure time constraints of the university students in physical education and sport scholls on their leisure time motivation: Bartın university sample. International Journal of Recreation and Sports Science, 2(1), 39-52. Retrieved from https://dergipark.org.tr/en/pub/ijrss/issue/41363/490963 
Gümüş, H. (2019). Sportspersonship Orientation in X Generation. OPUS International Journal of Society Researches, 10(17), 738-755. https://doi.org/10.26466/opus.524867

Gümüş, H., Ayna, Ç., \& Yildirim, İ. (2018). Reviewing Attitudes of Women towards Leisure Activities in Terms of Different Variables. Turkish Journal of Sport and Exercise, 20(3), 224-229. https://doi.org/10.15314/tsed.491629

Güngörmüş, H. A. (2007). Determination of recreational exercise participation motives of individuals using private health and fitness centers ( $\mathrm{PhD}$ thesis). Ankara: Gazi University.

Güngörmüş, H. A., Yenel, F., \& Gürbüz, B. (2004). Examination of recreational motives of individuals: demographic differences. International Journal of Human Science, 11(1), 373-386. https://doi.org/10.14687/ijhs.v11i1.2165

Güngörmüş, H. A., Yetim A. A., \& Çalık, C. (2006). Research on spending the leisure time of lecturers worked in schools of physical education and sports in Ankara. Kastamonu Education Journal, 14(2), 653-666.

Güngörmüş, H. A., Yumuk, E. D., Bolat, C., \& Karakullukçu, Ö. F. (2019). Analysis of attitudes towards leisure activities and levels of involvement of individuals doing racket sports with recreational purposes. 2nd International Recreation and Sports Management Congress. Muğla (Oral Presentation) (No: 5189655).

Gürbüz, B., \& Henderson, K. (2013). Exploring the meanings of leisure among Turkish university students. Croatian Journal of Education, 15(4), 927-957. https://doi.org/10.17718/tojde.54964

Gürbüz, B., \& Henderson, K. (2014). Leisure activity preferences and constraints to leisure: Perspectives from Turkey. World Leisure Journal, 56(4), 300-316. https://doi.org/10.1080/16078055.2014.958195

Gürpınar, B. (2014). Adaptation of the attitudes to moral decision-making in youth sport questionnaire-2 into Turkish culture: A validity and reliability study. Education \& Science, 39(176), 405-412. https://doi.org/10.15390/EB.2014.3643

Güven, Ö., \& Öncü, E. (2006). Family Factor in Physical Education. Journal of Social Policy Studies, 10(10), 81-90.

Johnson, C. G., Vargas, T. M., Watson, J. C., \& Pedersen, W. C. (2018). Coaching efficacy, moral disengagement, and responses to hostile aggression among high school coaches. International Journal of Sports Science \& Coaching, 13(6), 828-840. https://doi.org/10.1177/1747954118787065

Kara, F. M., Sarol, H., \& Güngörmüş, H. A. (2019). “Attitudes are contagious": Leisure attitude and passion of university students. International Education Studies, 12(7), 42-48. https://doi.org/10.5539/ies.v12n7p42

Kline, R. B. (2011). An easy guide to factor analysis. New York: Routledge.

Kohlberg, L., \& Hersh, R. H. (1977). Moral development: A review of the theory. Theory into practice, 16(2), 53-59. https://doi.org/10.1080/00405847709542675

Lee, M. J., Whitehead, J., \& Ntoumanis, N. (2007). Development of the attitudes to moral decision-making in youth sport questionnaire (AMDYSQ). Psychology of Sport and Exercise, 8(3), 369-392. https://doi.org/10.1016/j.psychsport.2006.12.002

Mallia, L., Lucidi, F., Zelli, A., Chirico, A., \& Hagger, M. S. (2019). Predicting moral attitudes and antisocial behavior in young team sport athletes: A self-determination theory perspective. Journal of Applied Social Psychology, 49(4), 249-263. https://doi.org/10.1111/jasp.12581

Miller, W. B., Roberts, C., \& Ommundsen, Y. (2004). Effect of motivational climate on sportspersonship among competitive youth male and female football players. Scandinavian Journal of Medicine \& Science in Sports, 14, 193-202. https://doi.org/10.1111/j.1600-0838.2003.00320.x

Morton, K. L., Atkin, A. J., Corder, K., Suhrcke, M., \& Van Sluijs, E. M. F. (2016). The school environment and adolescent physical activity and sedentary behaviour: a mixed-studies systematic review. Obesity reviews, 17(2), 142-158. https://doi.org/10.1111/obr.12352

Mouratidou, K., Chatzopoulos, D., \& Karamavrou, S. (2007). Moral development in sport context: Utopia or reality. Hellenic Journal of Psychology, 4(2), 163-184.

Orhan, R. (2019). The importance of physical activity and sports in child development. Klrkkale University Journal of Social Sciences, 9(1), 157-176.

Özsarı, A., \& Altın, M. (2017). The moral decision making attitudes of the athletes attending to sport training centers. International Journal of Cultural and Social Studies, 3(1), 133-145. 
Sarol, H., \& Çimen, Z. (2017). Why people participate leisure time physical activity: A Turkish perspective. Pamukkale Journal of Sport Sciences, 8(1), 63-72.

Sezen-Balçıkanlı, G., Aktaş, İ., \& Sezen, M. (2018). The Turkish adaptation study of sportspersonship coaching behaviors scale. The Journal of Physical Education and Sport Sciences, 16(4), 236-245. https://doi.org/10.1501/Sporm_0000000370

Şirin, P., Arif, Ö., Hamdi, P., Bülent, F., \& Aydın, P. (2017). A Scrutiny on the moral decision-making attitudes of the youth sportspeople in combat branches. European Journal of Physical Education and Sport Science. https://doi.org/10.5281/zenodo.995649

Soulliard, Z. A., Kauffman, A. A., Fitterman-Harris, H. F., Perry, J. E., \& Ross, M. J. (2019). Examining positive body image, sport confidence, flow state, and subjective performance among student athletes and non-athletes. Body image, 28, 93-100. https://doi.org/10.1016/j.bodyim.2018.12.009

Spruit, A., Kavussanu, M., Smit, T., \& IJntema, M. (2019). The relationship between moral climate of sports and the moral behavior of young athletes: A multilevel meta-analysis. Journal of youth and adolescence, 48(2), 228-242. https://doi.org/10.1007/s10964-018-0968-5

Trevino, L. K., Hartman, L. P., \& Brown, M. (2000). Moral person and moral manager: How executives develop a reputation for ethical leadership. California Management Review, 42(4), 128-142. https://doi.org/10.2307/41166057

Y1ldiz, Y. (2016). The relationship between fan identification and moral disengagement of physical education and sports students. Educational Research and Reviews, 11(7), 402-410. https://doi.org/10.5897/ERR2015.2541

Yıldız, Y., Yıldız, K., \& Tutucu, B. (2019). Investigation of Moral Decision Making Attitudes of Young Athletes. 2nd International Recreation and Sports Management Congress. 11-14 April, (Editor: Bülent Gürbüz, Hamdi Alper Güngörmüş, pp. 104-107).

\section{Copyrights}

Copyright for this article is retained by the author(s), with first publication rights granted to the journal.

This is an open-access article distributed under the terms and conditions of the Creative Commons Attribution license (http://creativecommons.org/licenses/by/4.0/). 